\title{
Experimental investigation of a moving-bed heat storage thermochemical reactor with $\mathrm{SrBr}_{2} / \mathrm{H}_{2} \mathrm{O}$ couple \\ Lauren Farcot $^{a, b}$, Nolwenn Le Pierrès ${ }^{a *}$, Jean-François Fourmigué ${ }^{c}$ \\ *Corresponding author: nolwenn.le-pierres@univ-smb.fr \\ ${ }^{a}$ Université Savoie Mont Blanc - CNRS, LOCIE, Le Bourget-du-Lac, 73370, France, \\ ${ }^{b}$ CEA/DTBH/SBRT/LSHT, Le Bourget-du-Lac, 73370, France \\ ${ }^{c}$ CEA/DRT/LITEN/DTBH, Grenoble, 38000, France
}

\begin{abstract}
:
This study investigates a moving-bed thermochemical reactor with hydrated salt and humid air flow, suitable for building heating applications. A well-instrumented reactor prototype, developed to produce a heating power up to $1 \mathrm{~kW}$, allowed analysing the functioning of the reactor. The $\mathrm{SrBr}_{2} \cdot \mathrm{H}_{2} \mathrm{O} / \mathrm{SrBr}_{2} \cdot 6 \mathrm{H}_{2} \mathrm{O}$ pair was used and allowed reaching reactor temperatures up to $41^{\circ} \mathrm{C}$ and specific heating powers of 1.7 to $4.6 \mathrm{~kW} / \mathrm{m}^{3}$ of reactor bed. Once the thermal steady state was reached, the temperature was homogeneous throughout the bed. This study shows the impact of the air humidity at the reactor inlet on the reactor performances and shows the feasibility of continuous thermochemical heat storage in a moving bed reactor with hydrated salt. Finally, this study highlighted the advantages and limitations of moving bed reactors for thermochemical storage applications.
\end{abstract}

\section{Keywords:}

Heat storage, building heating, thermochemical process, experimentation, solar heat, $\mathrm{SrBr}_{2} / \mathrm{H}_{2} \mathrm{O}$.

\section{Introduction and context}

Energy consumption in buildings represents about $20 \%$ of the energy consumption in the world (40\% in Europe) and the main share of this energy (50\% in the world) is used for space heating ${ }^{[1]}$. Solar heat could be a good option to decrease fossil fuels consumption in buildings, but this energy source is intermittent. Thus, development of efficient and convenient energy storage systems is an important step toward a better management of this renewable energy as it leads to time adequacy between the energy resource and demand ${ }^{[2]}$.

Heat storage technologies available nowadays, using sensible or latent heat ${ }^{[3-4]}$, are efficient and reliable for daily and weekly storage but they present important heat losses for longer time scales. Thermochemical technologies are thus a good alternative for long-term heat storage because heat is stored as a chemical potential and there is no heat losses during the storage phase ${ }^{[5-7]}$.

Indeed, thermochemical energy storage (TES) systems are based on a phenomenon of the form:

$$
\mathrm{S}_{0}+v \mathrm{G} \Leftrightarrow \mathrm{S}_{1}+\Delta \mathrm{h}_{\mathrm{r}}^{0}
$$

The decomposition (endothermic phenomenon) of the solid $\left(\mathrm{S}_{1}\right)$ into the solid $\left(\mathrm{S}_{0}\right)$ and gas $(\mathrm{G})$ requires a heat input of $\Delta \mathrm{h}_{\mathrm{r}}$. Thus, for seasonal storage purpose, the reactive solid $\left(\mathrm{S}_{1}\right)$ can be heated by solar energy during the summer period. It is the charging phase of the process. Inversely, during the winter period, $\left(S_{0}\right)$ can react with gas $(G)$ to form $\left(S_{1}\right)$. This phenomenon is exothermic and corresponds to the discharging phase of the process (heat recovery period). 
The solid reactants must be low cost, non-toxic, non-corrosive and have sufficient energy storage density, to expect large scale technological development. Energy storage density (or energy density) in this case is the amount of heat that can be stored per unit mass or volume. In the following work, as the application aimed at is building integration, the volumetric energy density will be used. Reactive pairs can be of several sorts and different reactive gases can be used for thermochemical systems $\left(\mathrm{NH}_{3}, \mathrm{H}_{2} \mathrm{O}, \ldots\right)$. In this paper, focus is put on a reactive pair using water as reactive gas. Literature's data show that a large temperature range can be reached using different reactive pairs (from ambient temperature to several hundred degrees) ${ }^{[5-6]}$. A large number of studies has been carried out in the last years in the field of TES, especially regarding thermochemical material development and improvement of their properties (energy storage density, thermal conductivity, cycle stability ...) ${ }^{[8-11]}$. In comparison, fewer investigations have been performed to develop thermochemical reactor technologies ${ }^{[12-15]}$, whereas it is an important aspect to enhance heat and mass transfer in the system. Indeed, the energy density of the storage material is usually a lot larger than the energy density of the whole storage system ${ }^{[16]}$. Optimizing the design of the reactor thus allows achieving a maximum conversion of the reactant and increasing the power and energy density of the reactor.

TES technologies can work in open mode, crossed by humid air at atmospheric pressure or in closed mode with pure $(\mathrm{G})$ vapour, usually at low pressure. The closed mode allows a better control of the operating conditions in the reactor and favours the reaction kinetics but it increases the technical constraints on the process (airtightness, non-standard components ...). The open mode, at atmospheric pressure, allows avoiding these constraints. Thus, it could lead to a simpler and cheaper reactor conception ${ }^{[17]}$.

Additionally to the open or closed operating mode, two different reactor types can be distinguished for TES: integrated or separate reactors. In an integrated reactor, the material is stored in the same tank where it reacts. On the contrary, with a separate reactor, the reactor where the charging and discharging phases take place is separated from the thermochemical material storage reservoir. Each technology presents advantages and drawbacks. The main advantage of separate reactors is the dissociation between the thermal power and the storage capacity of the installation, which increases the storage density of the process because there is no need for vapour diffusers and heat exchangers integrated into the reactor. In a separate reactor, only the required amount of reactant is heated, making the charging and discharging phases more efficient. Moreover, the heat and gas transfers can be optimized in a separate reactor by stirring of the solid reactant. The separate reactor technology allows to work in steady-state, what can provide constant thermal power output. Finally, in this configuration, the technological constraints are focused on the reactor and the storage functions are simplified, making the storage reservoir cheaper, and a smaller reactor can be designed compared to the integrated one, which results also in a smaller thermal inertia and in lower sensible heat loss. However, this technology implies transportation of the solid material and therefore, a transport system has to be added, resulting in a more complex design and the addition of mechanical components and of power consumption for transportation. Transportation can also damage the material and have an impact on its cycling stability ${ }^{[6-7]}$.

The separate reactor technology has not been fully investigated yet. Indeed, most of the works on TES systems deal with integrated reactor technology ${ }^{[6-7,12,27]}$. A lot of studies regarding integrated reactor technology have investigated packed bed technologies, but vibrating bed reactors ${ }^{\text {[27], }}$ fluidized bed reactors ${ }^{[13,20]}$ and a rotary kiln reactor ${ }^{[14]}$ have also been adapted to thermochemical storage. 
The originality of the present work is the choice to develop an open mode moving bed reactor with humid air as the reactive gas and heat carrying fluid, which will be described in the next section. This type of reactor adapted to solid/gas thermochemical reactions allows to get technological simplicity of the process components, a good contact between the solid and the gaseous phases to improve heat and mass transfers, a low power consumption both for solid transportation and for air flow, avoiding the use of a stirring device which can cause the attrition of the solid, and reducing the air volume according to the solid phase in the reactor in order to reach the highest storage density and the highest outlet air temperature during the discharging phase.

To the authors' knowledge, this technology has already been investigated by one team in the Institute for Thermodynamics and Technical Engineering (ITW) ${ }^{[15]}$ for space heating application, using zeolite and salt impregnated zeolite as storage materials. The storage system consisted of a reactor of approximately 301 and a sorbent storage reservoir of 2001 . This prototype was experimentally investigated under various air humidities and heating demands. The main challenge observed was to maintain a uniform solid flow through the reactor. A ratio of electric consumption of the solid material transportation to useful thermal power of $13 \mathrm{~W}_{\mathrm{el}} / \mathrm{kW}_{\text {th }}$ was measured, assuming an energy density of approximately $0.67 \mathrm{GJ} / \mathrm{m}^{3}{ }^{[7]}$. This study showed that the moving bed reactor is adapted for solid/gas thermochemical heat storage.

However, the use of zeolite in thermochemical storage is not adapted to a large panel of applications because of the short range of discharging temperature that can be reached $\left(40-80{ }^{\circ} \mathrm{C}\right)$, moreover, this material presents a lower energy density compared to thermochemical hydrated salts [21]. This is why the aim of the present project is to adapt the moving bed reactor technology to the use of hydrated salts. A prototype was developed and tested in conditions close to the ones expected in a real solar building and allowed analysing the functioning of the moving bed reactor in a TES system with hydrated salt. The objective of this paper is thus to present the process, the experimental results and the limits of the prototype to prove the feasibility of a hydrated salt moving bed reactor for long term heat storage.

\section{Process description}

\subsection{Process general description}

The process in the case of a fixed bed with zeolite and its implementation into a building were described in ${ }^{[18]}$. Possible implementation of the storage system in a solar building, and the two functioning phases are presented in Figure 1. Desorption takes place in summer (Figure 1a), using the heat delivered by solar collectors. Heat is released when the humid inside air flows through the reactor (Figure 1b) so that the following heat exchanger receives warmer, dry air. The heat of the outflowing air is transferred to the incoming fresh air. This warm air is then used for heating purposes.

The studied reactor here is a moving bed, that is a circulating bed with the same porosity as a fixed bed. The solid moves downwards slowly from the top to the bottom of the reactor by gravity and the humid air flow is cross flow with respect to the falling solid (Figure 2). The transportation of vapour through the reactor is thus due to the air flow. The bed behaviour is close to a packed bed one, as the solid motion is really slow $(\sim 0.01 \mathrm{~m} / \mathrm{h})$ compared to the air velocity $(\sim 200 \mathrm{~m} / \mathrm{h})$. But contrarily to a fixed packed bed, the state of the solid changes from the top to the bottom and thus air flowing through the top of the reactor does not react in the same way as air flowing through the middle or the bottom of the reactor. To prevent air from exiting the reactor vertically by the top or 
the bottom of the reactor, two inert zones are placed at the top and the bottom of the reactor and filled with the reactive salt: the air pressure drop in this bed should allow neglecting the air flow in the vertical direction. The solid velocity is regulated by the rotation speed of a rotary valve at the bottom of the lower inert zone (with a low rotation speed of 0.15 to $0.5 \mathrm{rph}$ ).

a) Charging

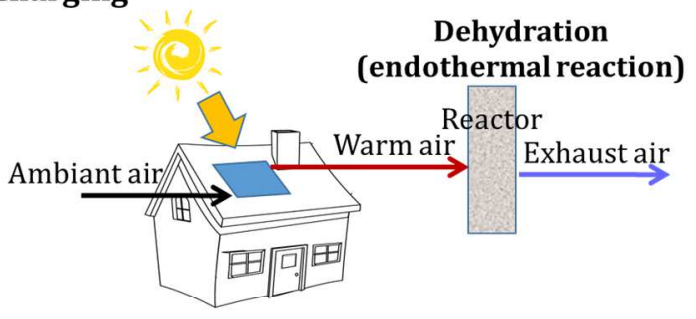

b) Discharging

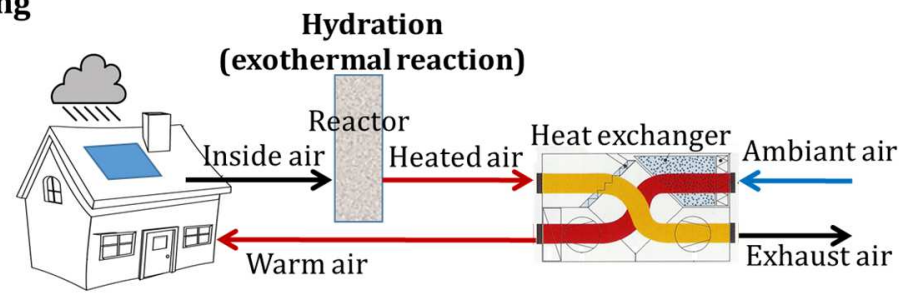

Figure 1 : Possible implementation of the storage system in a solar building with a) functioning in the charging phase and $b$ ) in the discharging phase
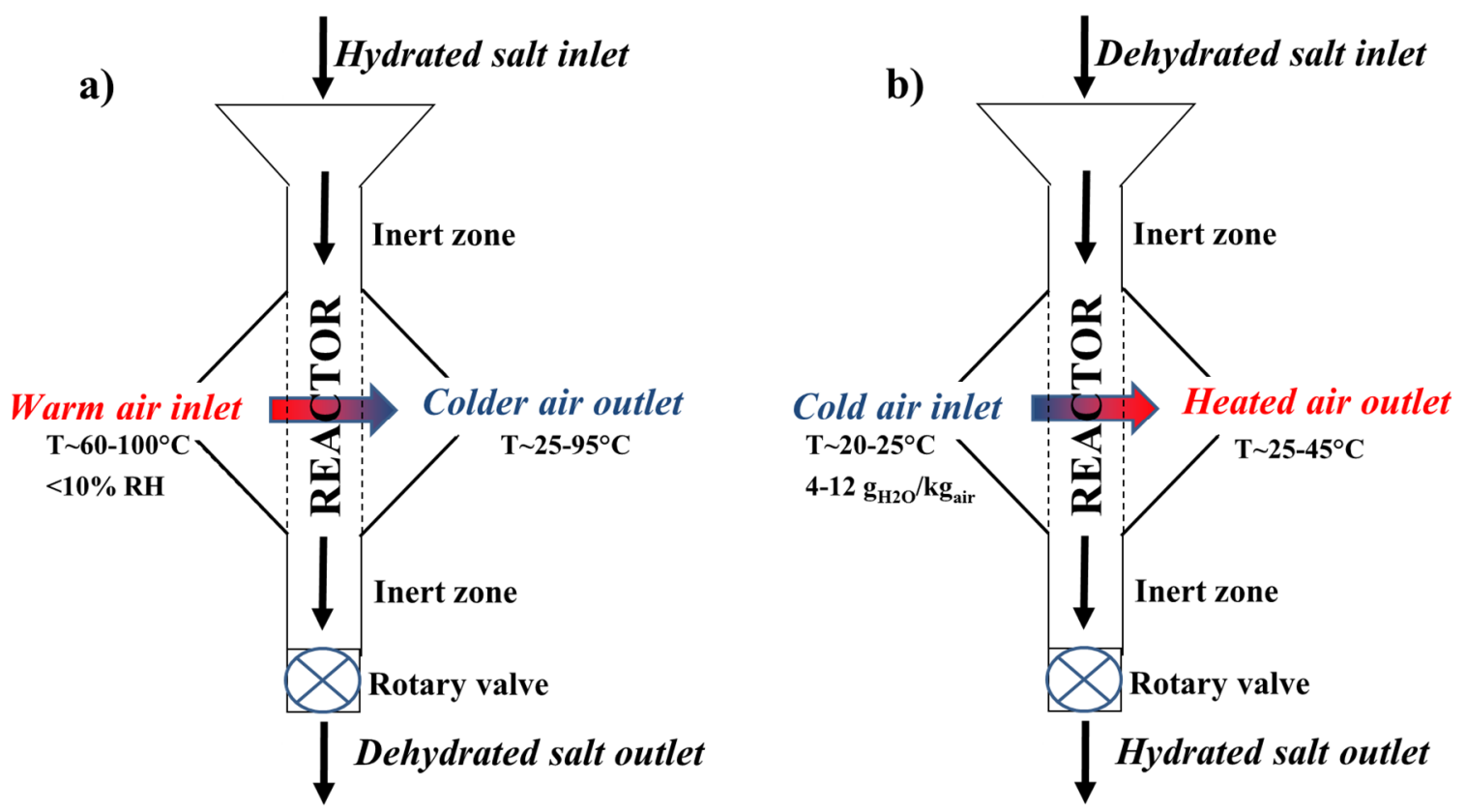

Figure 2 : Process description and functioning. a) Charging phase. b) Discharging phase.

An external heat exchanger transfers the energy from the outlet air of the reactor to the house during the discharging phase or from solar collectors to the inlet air of the reactor during the charging phase. As this heat exchanger is separated from the reactor, it does not influence the reactor functioning and design. 
Numerical study of the reactor ${ }^{[23]}$ has proven that the reaction front in the bed would approximately follow a diagonal of the reactor at steady state, in the case of an optimal solid salt velocity with respect to the air flow and humidity (Figure 3). The optimal solid velocity corresponds to the case when all the solid has reacted when it goes out of the reactor and when the entire volume of the reactor is used efficiently ${ }^{[23]}$. The reaction takes place along a sharp reaction front separating the bed in a fully hydrated part $(X=1$, red) and a fully dehydrated part $(X=0$, blue). An inertia effect appears at the entrance of the unreacted solid (top of the reactor). Along this layer of the reactor, the reaction is more diffuse than at the bottom of the reactor, as the dehydrated solid is colder than in the rest of the bed, so the reaction kinetic is higher but the air velocity is also higher (due to higher porosity of the bed) and increases the reaction front thickness. Contrarily to an integrated fixed bed reactor system, this reactor can reach steady-state, what can provide constant thermal power output. The power output during the discharging phase depends mostly on the reactor thickness, the cross section of the reactor and on the air humidity ${ }^{[23]}$.

a)

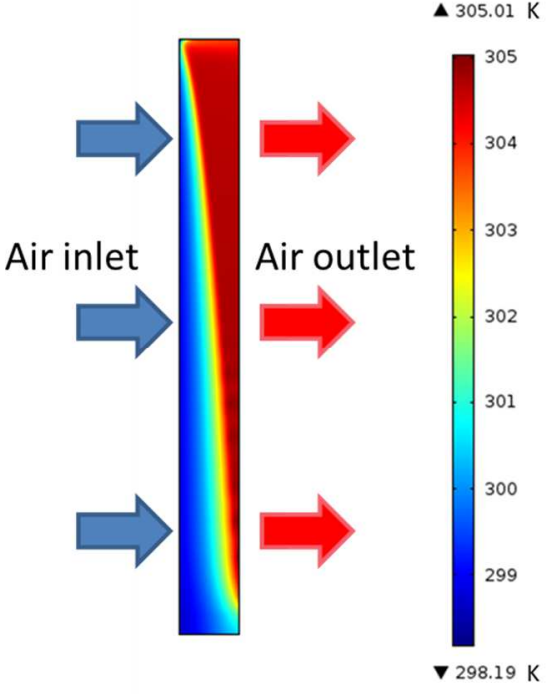

b)

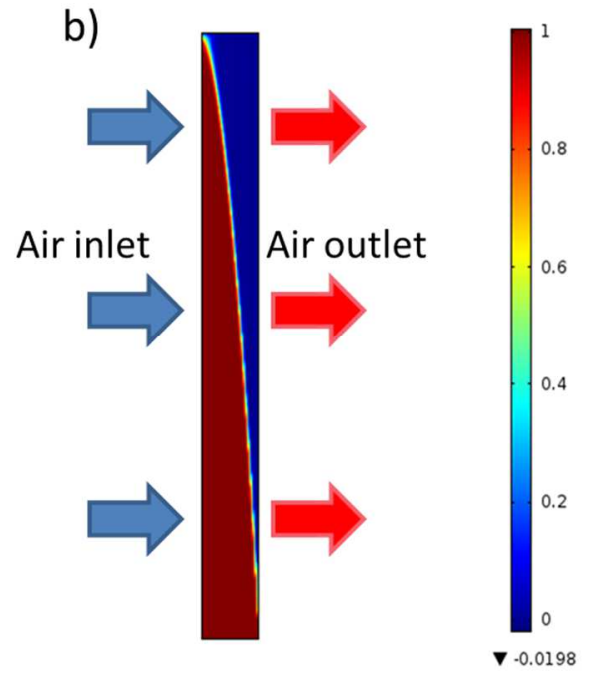

Figure 3 : Typical simulated temperature field and reaction rate in the reactor during the discharging phase [22]. a) Temperature profile; b) advancement profile. Here, the solid velocity was adjusted such that the salt just reaches fully hydrated state at the bottom of the reactor

\subsection{Reactant choice}

Possible reactive pairs for TES systems are numerous and different reactive gases can be used $\left(\mathrm{NH}_{3}, \mathrm{H}_{2} \mathrm{O}, \ldots\right)$. In this project, as the system is open, the reactive gas is obviously water. As thermochemical hydrated salts present a high energy density, the aim of this project was to use hydrated salts as solid reactant. The corresponding reactions allow reaching a large range of equilibrium temperatures, storage densities or material characteristics. The choice of the salt in this case follows the same criteria as for other open TES systems: the solid must be low cost, non-toxic, non-corrosive and have high energy storage density, to expect further large scale technological development. The reactive pair chosen for this study is thus $\mathrm{SrBr}_{2} \cdot \mathrm{H}_{2} \mathrm{O} / \mathrm{SrBr}_{2} \cdot 6 \mathrm{H}_{2} \mathrm{O}$. In this case, the advancement of the reaction is $\mathrm{X}=0$ when the salt is in its mono-hydrated form $\mathrm{SrBr}_{2} \cdot \mathrm{H}_{2} \mathrm{O}$ and the advancement of the reaction is $\mathrm{X}=1$ when the salt is in its hexa-hydrated form $\mathrm{SrBr}_{2} \cdot 6 \mathrm{H}_{2} \mathrm{O}$. When 
considering the whole bed, the advancement of the reaction can change progressively between 0 and 1 and represents the average state of the salt in the bed.

The choice of this couple was made regarding the equilibrium of the reaction that can provide the target temperature range for a solar building heating application. Furthermore, this material presents a good energy density $\left(\approx 300 \mathrm{kWh} / \mathrm{m}^{3}\right.$ ie $\left.1 \mathrm{GJ} / \mathrm{m}^{3}\right)$ and its physico-chemical properties are available in the literature, as this salt has been investigated and characterized in former studies ${ }^{[12,19]}$. It is also stable, and has been highlighted as one of the most promising salt for heat storage at higher temperature. For these reasons, this material was chosen for this study despite the corrosion issue that can be encountered with steel ${ }^{[2]}$ and its quite high cost ${ }^{[11]}$. This salt has already been used in thermochemical storage prototypes in previous research projects ${ }^{[12,19,24]}$, both in closed and open systems, but has never been tested in a moving bed continuous reactor.

\subsection{Prototype design}

A prototype was designed and built to prove the feasibility of thermochemical heat storage in a moving bed with hydrated salts. The reactor bed is $0,95 \mathrm{~m}$ high, $0,95 \mathrm{~m}$ wide and $10 \mathrm{~cm}$ thick (Figure 4). This thickness is low enough to avoid large air pressure drop in the reactor, but is large enough to allow theoretically the solid to flow quasi-uniformly. The reactor walls are in stainless steel to avoid corrosion, and the air diffuser and collector are separated from the reactor by a stainless steel mesh with $70 \mu \mathrm{m}$ holes. The air cross section of the reactor can be adjusted (reduced) by adding stainless steel walls along the mesh. To prevent air from exiting the bench by the top or the bottom of the reactor, the two inert zones at the top and the bottom of the reactor are $30 \mathrm{~cm}$ high. A stainless-steel reservoir receives the salt that falls from the rotary valve at the bottom of the reactor, and the salt can be manually transferred back to the feeding funnel (for this feasibility study, the solid transportation has not been automated).

Air can be flown through the reactor at a temperature between 0 and $100{ }^{\circ} \mathrm{C}$, a relative humidity between 0 and $90 \%$ and a volumetric flow rate between 60 and $400 \mathrm{~m}^{3} / \mathrm{h}$, after being treated in a dedicated air-handling unit. 

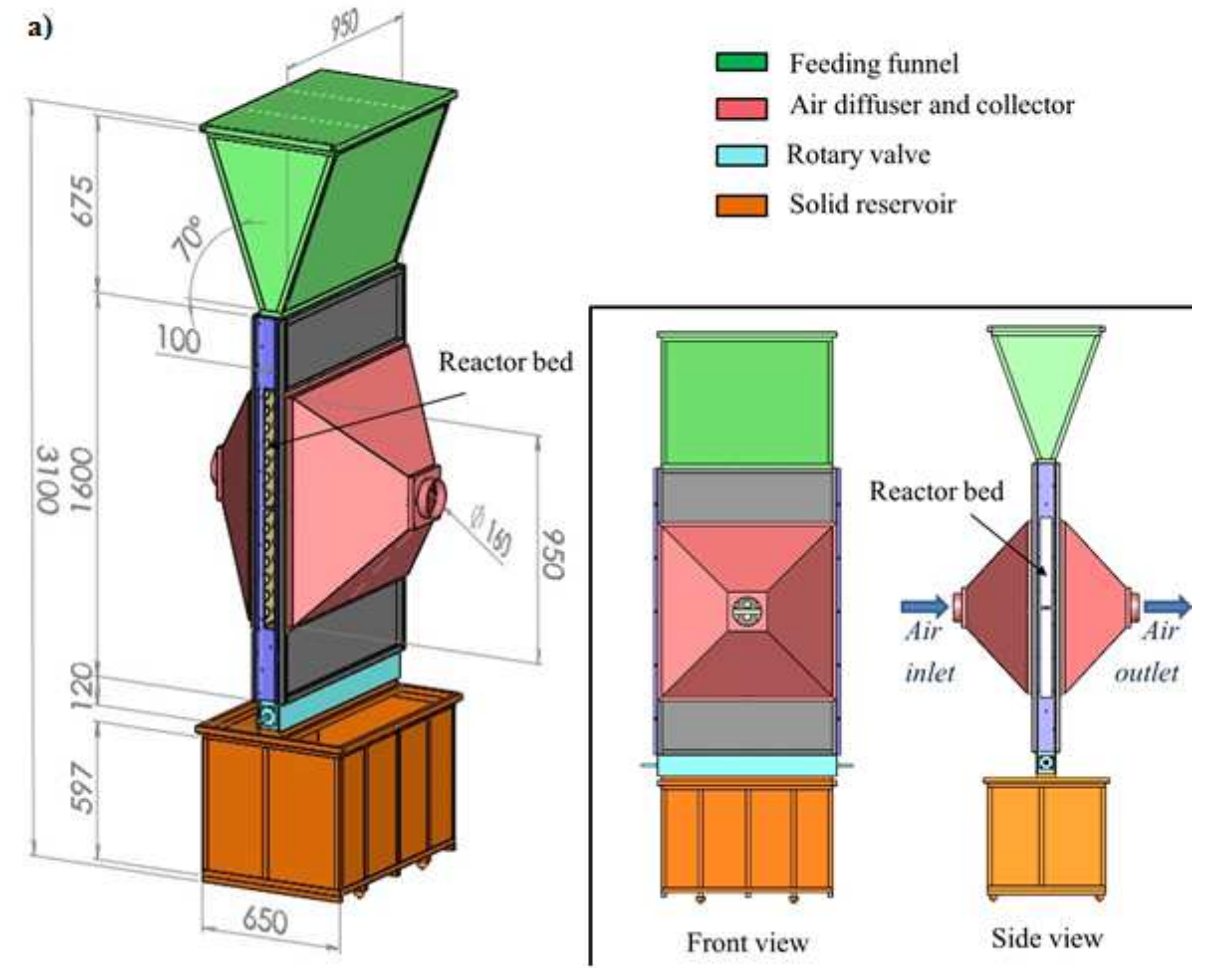

b)

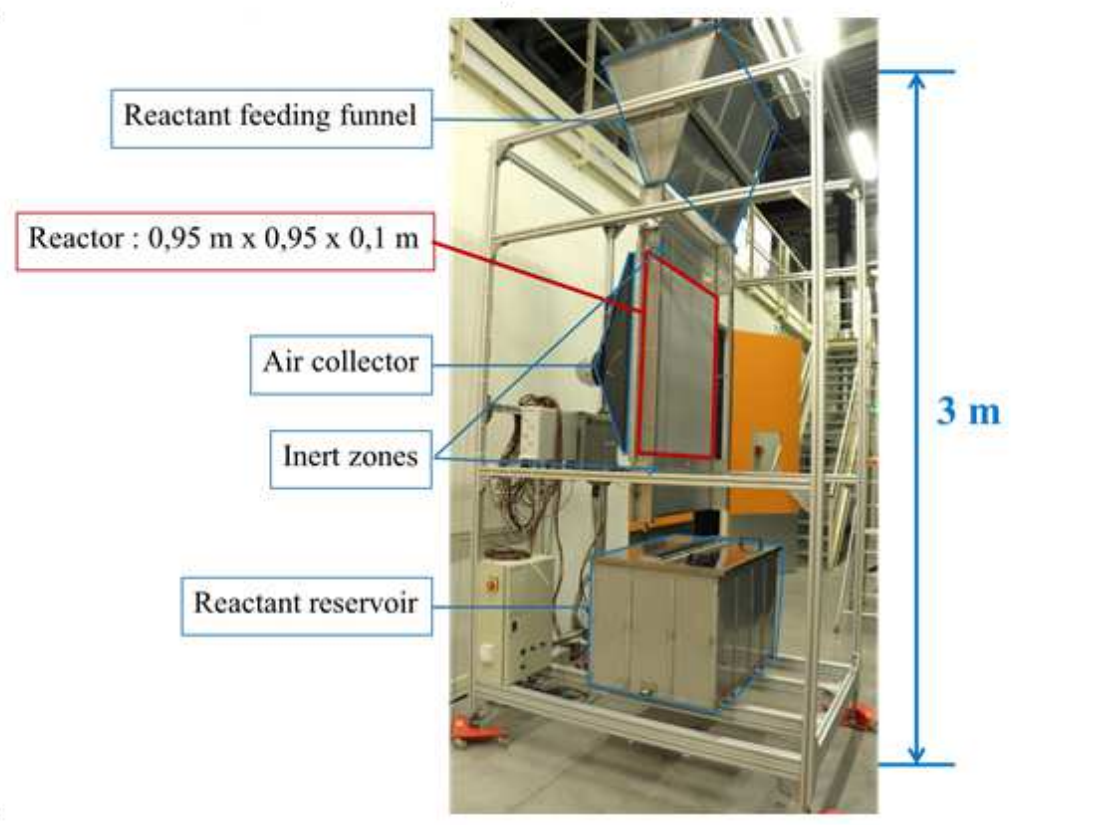

Figure 4 - a) Reactor scheme and dimensions and b) picture of the protoype.

\subsection{Prototype instrumentation}

The reactor was equipped by 67 thermocouples with a precision $+/-0,2^{\circ} \mathrm{C}$ positioned as presented in Figure 5, both inside the bed and in the air distributor and collector. The air speed is measured at the inlet of the distributor with a precision $+/-0,2 \mathrm{~m} / \mathrm{s}$. The relative air humidity is measured at the air inlet and outlet ducts with a precision $+/-3,4 \% \mathrm{RH}$, and the mass of the reactor is measured using four strain gauges with a precision $+/-0,39 \mathrm{~kg}$ each. This mass measurement allows 
evaluating the average advancement of the reaction $\mathrm{X}$ in the reactor, but with a relative uncertainty of $42 \%$ only.

The different measurements are recorded every $10 \mathrm{~s}$ along the tests. Pressure losses observed through the reactor bed were not registered automatically, but could be measured between 1500 and $1700 \mathrm{~Pa}$ for all the experimental conditions. This pressure drop is acceptable in the framework of a building air ventilation system.

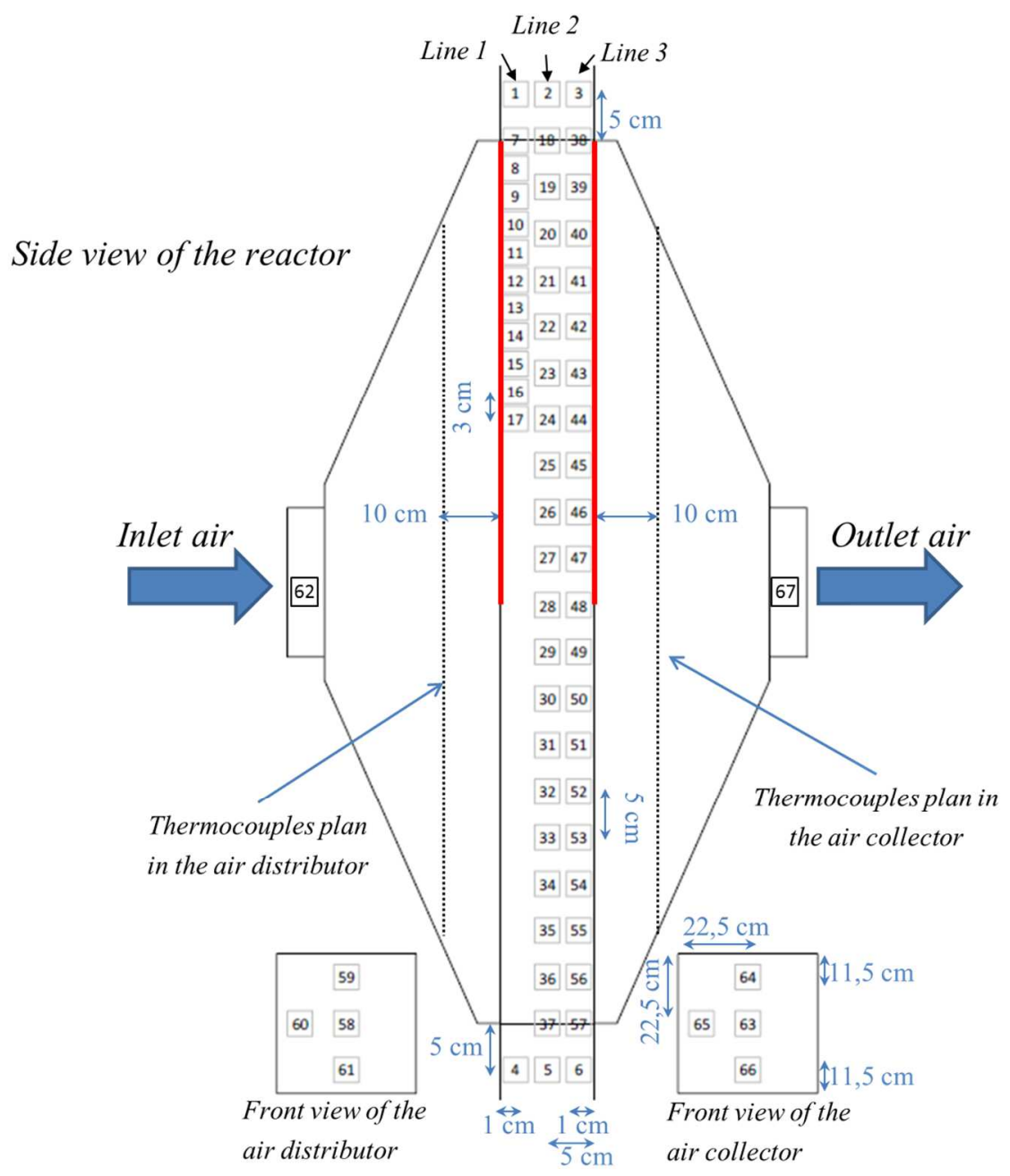

Figure 5 : Thermocouples positioning in the reactor bench

\section{Experimental study}

\subsection{Experimental conditions}

As the discharging phase is the most critical phase of the process (as it reveals the discharging temperature that can be used for building heating and the power produced by the system), tests will be presented for this phase only. Between each discharging test, charging tests were performed to regenerate the hydrated salts at $75^{\circ} \mathrm{C}, 0,6 \mathrm{~g} / \mathrm{kg}$ absolute humidity (corresponding to $\sim 95 \mathrm{~Pa}$ vapour 
pressure), but will not be discussed. Considering the $\mathrm{SrBr}_{2} \cdot \mathrm{H}_{2} \mathrm{O} / \mathrm{SrBr}_{2} \cdot 6 \mathrm{H}_{2} \mathrm{O}$ equilibrium curve ${ }^{\text {[19] }}$ and the length of the charging tests, the salt could be considered fully in its monohydrated state at the beginning of each hydration test $(\mathrm{X} \sim 0)$. As the prototype has not been automated, discharging tests lengths were limited to about $10 \mathrm{~h}$.

For these experiments, a problem with the reactive material supply constrained us to use only half of the reactor, and stainless steel walls were added to block the air flow from the top half of the reactor section. These stainless steel walls are represented in red in Figure 5. Thus, only the thermocouples situated in the bottom-half of the bed will be analysed.

The experimental conditions chosen are presented in Table 1. After a transient period of about 15 minutes at the beginning of each test, these conditions were maintained at the set value with a range of $+/-0.5^{\circ} \mathrm{C}$ for the temperature, $+/-6 \%$ for the air flow and $+/-0.6 \mathrm{~g} / \mathrm{kg}$ maximum for the vapour mass fraction (with $+/-0.4 \mathrm{~g} / \mathrm{kg}$ vapour mass fraction averaged over $1 \mathrm{~h}$ for tests with inlet vapour mass fraction lower than $8 \mathrm{~g} / \mathrm{kg}$ ).

These experimental conditions correspond to possible conditions in real solar buildings during the discharging phase, as shown in Figure 1 and 2 . The inlet air temperature $\left(\sim 21^{\circ} \mathrm{C}\right)$ corresponds to air exiting the building and the reactor outlet air flows through a heat recovery unit (heat exchanger) from a double-flow controlled mechanical ventilation system. The vapour mass fraction of the inlet air corresponds to possible buildings air humidity during the winter season. 4,9 and $12 \mathrm{~g} / \mathrm{kg}$ vapour mass fraction correspond to $\sim 28 \%, 60 \%$ and $80 \%$ relative humidity at $21^{\circ} \mathrm{C}$, or $\sim 640 \mathrm{~Pa}, 1400 \mathrm{~Pa}$ and $1880 \mathrm{~Pa}$ respectively. The highest humidities tested would not happen often in real buildings during the winter season, but could happen during the spring or autumn, or for specific activities inside the dwelling. The solid velocity of $0,5 \mathrm{~cm} / \mathrm{h}$ corresponds to the optimal velocity in the air conditions of test $\mathrm{H} 3$. At that velocity, the salt just reaches full hydrated state at the bottom of the reactor: it allows obtaining the maximum outlet temperature of the air and the highest process energy density. A higher velocity of $1,5 \mathrm{~cm} / \mathrm{h}$ has also been tested (H6 test).

Table 1 : Experimental conditions

\begin{tabular}{cccccc}
\hline $\begin{array}{c}\text { Test } \\
\text { number }\end{array}$ & $\begin{array}{c}\text { Air flow } \\
\left(\mathrm{m}^{3} / \mathrm{h}\right)\end{array}$ & $\begin{array}{c}\text { Air inlet } \\
\text { temperature }\left({ }^{\circ} \mathrm{C}\right)\end{array}$ & $\begin{array}{c}\text { Inlet vapour mass } \\
\text { fraction }(\mathrm{g} / \mathrm{kg})\end{array}$ & $\begin{array}{c}\text { Inlet vapor } \\
\text { pressure }(\mathrm{kPa})\end{array}$ & $\begin{array}{c}\text { Solid velocity } \\
(\mathrm{cm} / \mathrm{h})\end{array}$ \\
\hline H1 & 140 & 25 & 4 & 0.64 & 0.5 \\
H2 & 110 & 21 & 12 & 1.88 & 0.5 \\
H3 & 93 & 22 & 9 & 1.38 & 0.5 \\
H4 & 90 & 22 & 9 & 1.38 & 0.5 \\
H5 & 80 to 100 & 21 & 12 & 1.88 & 0.5 \\
H6 & 80 to 100 & 21 & 9 & 1.40 & 1.5 \\
\hline
\end{tabular}

\subsection{Experimental results: reference test}

Discharging test $\mathrm{H} 3$ shown in Table 1 is considered as a reference case as it presents average humidity of inlet air and an optimal solid velocity. Figure 6 shows the measurements of the thermocouples located in the reactive zone in the middle of the reactor (Line 2, see Figure 5) during test H3. There is a good homogeneity of temperatures along this line of thermocouples, except for the thermocouple T28 which is located at the top end of the reactive zone (Figure 5) and is thus influenced by the solid inlet 
temperature. However, this side effect is limited, as it does not impact temperature T29 located $5 \mathrm{~cm}$ below T28.

The chemical steady state is long to establish. Evaluation of the advancement of the reaction in the reactor using the strain gauges showed that during $8 \mathrm{~h} 30 \mathrm{~min}$ of test $\mathrm{H} 3$, the average advancement of the reaction in the bed changes only from $\sim 1.7 \%$ to $\sim 8.7 \%$. The average advancement at steady state being larger than $50 \%$, as shown in Figure 3, the chemical steady state is not reached during this $\mathrm{H} 3$ test. However, the thermal steady state in the bed is reached when the temperature profiles do no longer change. For this test H3, this steady state is reached after about 40 min (Figure 6). After that period, the temperature of the bed increases slightly, but the main effect is a better homogeneity of temperature for each thermocouple line, and a decrease of the side effects at the top and bottom of the bed.

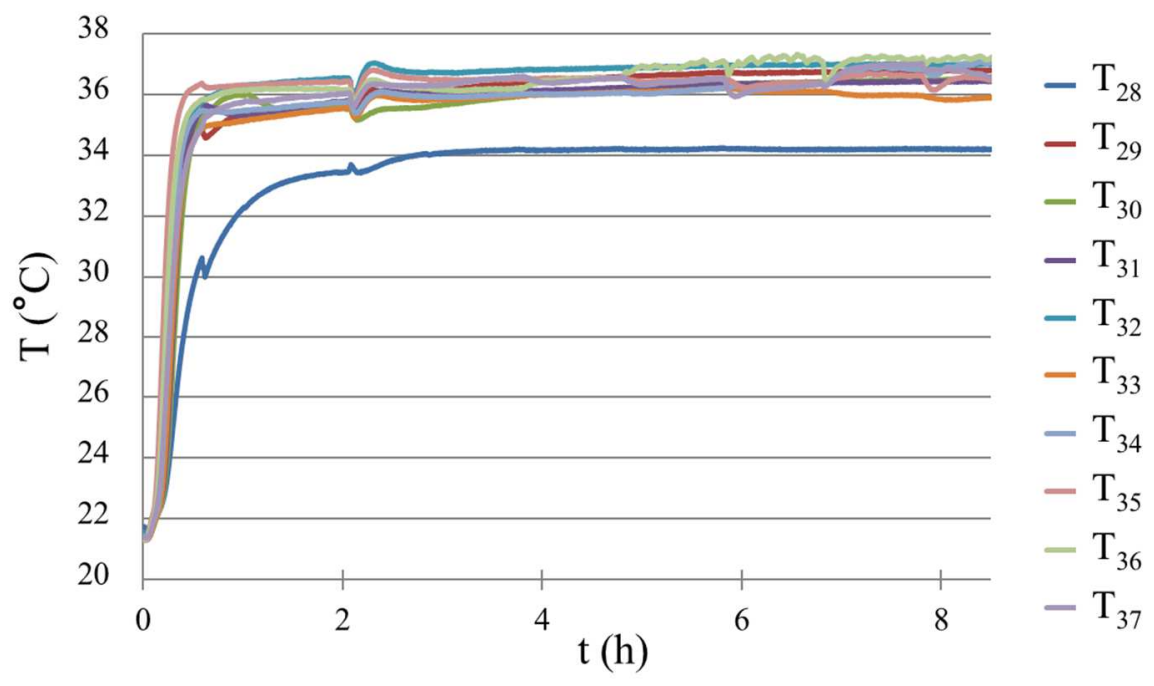

Figure 6 : Temperatures in the bed along the thermocouple line 2 (see Figure 5) during test H3

In Figure 7a, the average temperatures of lines 2 and 3 that correspond to thermocouples 28 to 37 and 48 to 57, respectively (Figure 5), are represented with the inlet and outlet ducts conditions $\left(T_{h, \text { in }}=T_{62}\right.$ and $\left.T_{h, o u t}=T_{67}\right)$, during test $H 3$. In Figure $7 \mathrm{~b}$ are presented the inlet and outlet humidities of the prototype. On both evolutions, the time needed to reach the thermal steady state is highlighted (dashed lines). There is a difference in temperature between the thermocouple lines 2 and 3 at the beginning of the test while the bed is heating up, with a logical delay of heating up of line 3 compared to line 2, linked to the evolution of the reaction front in the bed. Then, once the steady state is reached, the temperatures of the two lines of thermocouples are almost identical, which indicates that the temperatures become homogeneous in the bed.

The vapour mass fraction at thermochemical equilibrium between the flowing air and the salt close to the exit of the reactor $\left(w_{e q}\left(T_{\text {line } 3}\right)\right)$ can be calculated using data from ${ }^{[25]}$. The change in temperature of the bed influences the water vapour mass fraction at the outlet of the bed ( $w_{\text {out }}$ Figure $7 \mathrm{~b}$ ). Indeed, the evolution of the vapour mass fractions at the outlet of the reactor $w_{\text {out }}$ follows that of the equilibrium vapour mass fractions at the temperature of the bed $\left(w_{e q}\left(T_{\text {line }}\right)\right)$ at the beginning of the test : the quantity of steam consumed $\left(w_{\text {in }}-w_{\text {out }}\right)$ is therefore high at the beginning of the reaction and then stabilizes after reaching the thermal steady state. 

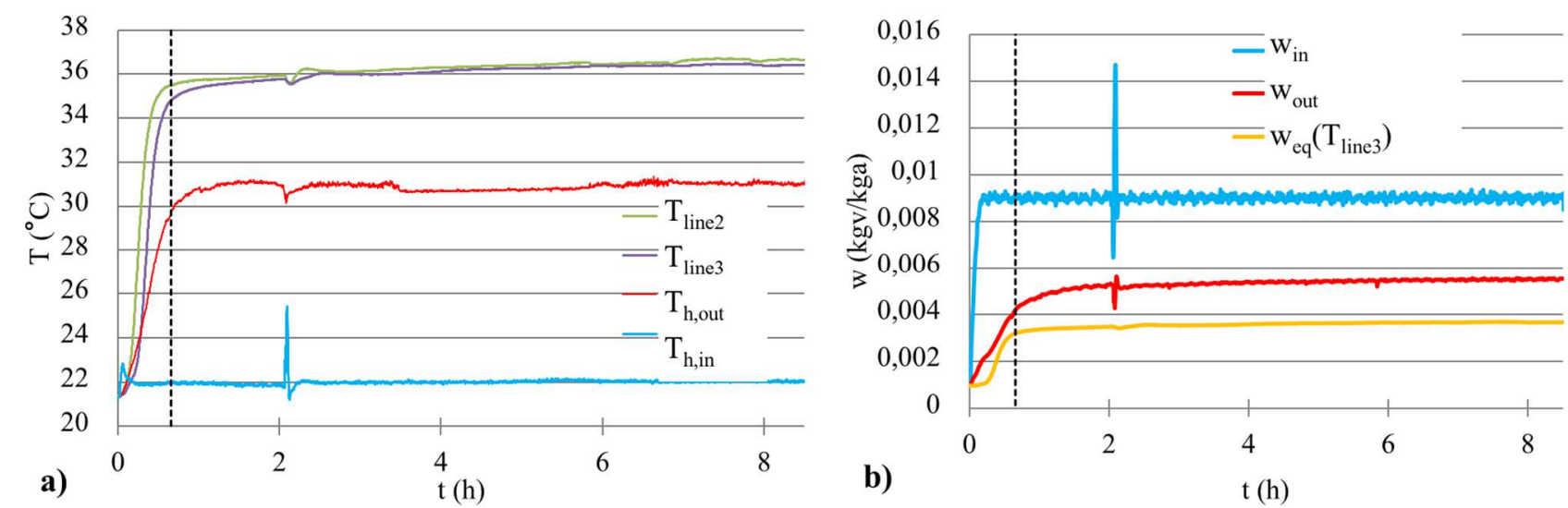

Figure 7 : Temperatures a) and vapour mass fractions b) in the prototype during test $\mathrm{H3}$

\subsection{Experimental results: Analysis of the test results}

When comparing the temperatures of the bed $T_{\text {line } 3}$ (Figure $7 \mathrm{a}$ ) with the temperature of the air in the air collector $T_{h, \text { out }}$, a strong temperature decrease from 36.5 to $31^{\circ} \mathrm{C}$ is observed. Moreover, the vapour mass fraction at thermochemical equilibrium between the flowing air and the salt close to the exit of the reactor $\left(w_{\text {eq }}\left(T_{\text {line } 3}\right)\right.$, Figure $\left.7 \mathrm{~b}\right)$ is $w_{\text {eq }}=3.7 \mathrm{~g}$ water $/ \mathrm{kg}$ dry air at steady state, but the measured value in the outlet duct $\left(w_{\text {out }}\right)$ is as high as $5.5 \mathrm{~g}$ water/kg dry air. Consequently, considering both thermal and mass balances over the bed, one can conclude that some of the air flow that has passed the reactor has not reacted or even interacted with the reactor salt. This unreacted (or partially reacted) air then mixes with the air that has actually crossed the salt bed in the collector and both increases its humidity and decreases its temperature, as illustrated in Figure 8. Air channelling is indeed created by a lack of homogeneity of the salt bed, as will be discussed in the next section. This 'bypass effect' should then be evaluated to be able to analyse the performances of the reactor.

In practice, the bypass effect must be reduced to a minimum, using adequate material and sufficient inert material above the reaction zone, but in the present results the bypass effect cannot be neglected and a bypass factor can be proposed to weigh the bypass effect. The bypass factor represents the fraction of the air that passes through the reactor bed without reacting with the salt (eq. (1)). The energy balance at the exit of the bed can be written as eq. (2) and the mass balance of water vapour as eq. (3).

$F_{b}=\frac{\dot{m}_{a, \text { bypass }}}{\dot{m}_{a, \text { in }}}$

$F_{b} \dot{m}_{a, \text { in }} C p_{h, \text { in }} T_{h, \text { in }}+\left(1-F_{b}\right) \dot{m}_{a, \text { in }} C p_{h, r} T_{\text {line } 3}=\dot{m}_{a, \text { in }} C p_{h, \text { out }} T_{63}$

where $C p_{h, \text { in }}=C p_{a}+w_{\text {in }} C p_{v}, C p_{h, r}=C p_{a}+w_{r} C p_{v}$ and $C p_{h, \text { out }}=C p_{a}+w_{\text {out }} C p_{v}$

$F_{b} \dot{m}_{a, \text { in }} w_{\text {in }}+\left(1-F_{b}\right) \dot{m}_{a, \text { in }} w_{r}=\dot{m}_{a, \text { in }} w_{\text {out }}$ 


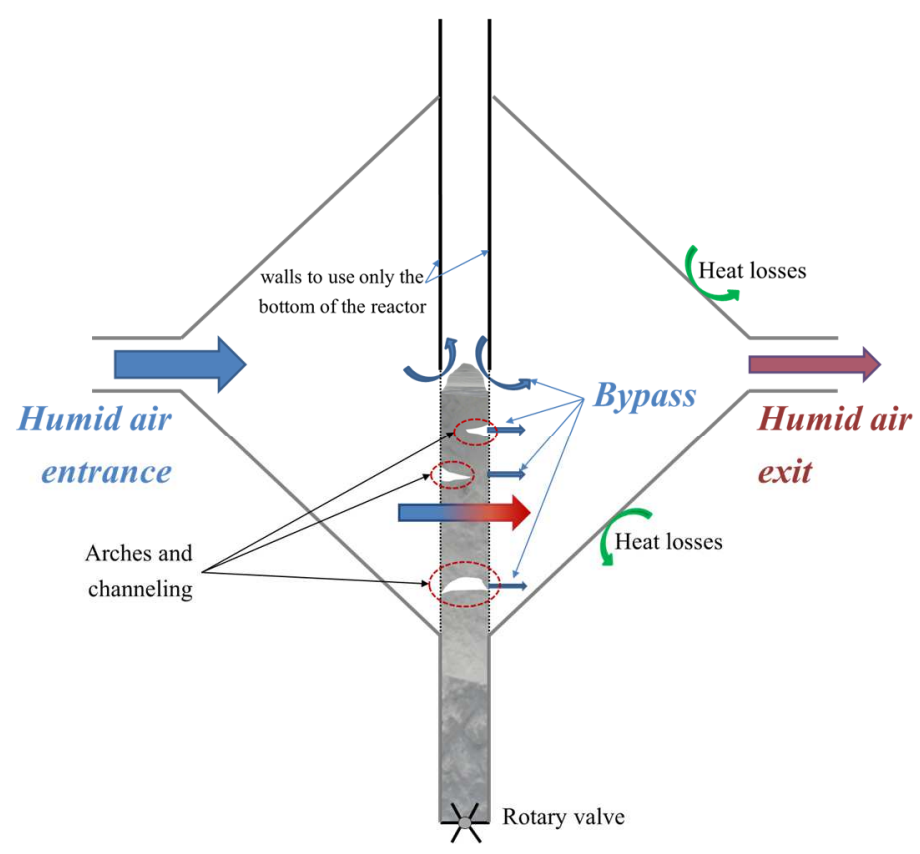

Figure 8 : Scheme of the bypass effect created by of the flowing inhomogeneity in the salt bed.

These equations allow to calculate both the bypass factor $F_{b}$ and the water vapour mass fraction in the reactor bed, $w_{r}$.

For test H3, the bypass factor at steady state is 0.33 . This value is high, as during the test, a lack of salt did not allow to have a large amount of salt in the inert zone above the reactor bed (Figure 8), thus a large bypass flow could appear at this point. In future experiments, with a larger amount of salt available, this bypass zone would be avoided and thus the bypass factor could be decreased. The water vapour mass fraction in the reactor bed, $w_{r}$ calculated using eq. (2) and (3), reaches $3.7 \mathrm{~g}$ water/kg dry air (or $580 \mathrm{~Pa}$ vapour pressure) in these conditions, which is exactly the vapour mass fraction at thermochemical equilibrium between the flowing air and the salt close to the exit of the reactor (Line 3), as calculated using data from ${ }^{[25]}$ and the Clausius - Clapeyron formula ${ }^{[12]}$ :

$p_{e q}(T)=p_{r e f} \exp \left(\frac{\Delta s_{r}^{\circ}}{R}-\frac{\Delta h_{r}^{\circ}}{R T}\right)$

where $p_{\text {ref }}$ is the reference pressure.

Using eq. (1) to (3) on experimental test allowed to calculate the water vapour mass fraction in the reactor bed, $w_{r}$. Comparison with equilibrium $w_{r}$ obtained using eq. (4) at $\mathrm{T}_{\text {line3 }}$ lead to the same value with a precision of $+/-3 \%$ at thermal steady state, thus validating the approach proposed for $\mathrm{F}_{b}$ calculation. This result also confirms the fact that the humid air that has actually crossed the salt bed reaches the thermochemical equilibrium state in the bed, as was shown by numerical simulations [23].

An important criterion to weigh the performance of such reactor is the power of the reactor which corresponds to the heat transferred to the air, $\dot{q}_{\text {heat }}$ between the inlet and outlet of the bench. At steady state, the reactor power is equal to the power generated by the reaction, $\dot{q}_{r}$, from which the thermal losses $\dot{q}_{\text {loss }}$ are subtracted. These different powers are presented in Figure 9. $\dot{q}_{r}$ can be calculated 
following the expression used in ${ }^{[26]}$, taking into account the bypass factor as stated in eq. (5), $\dot{q}_{\text {heat }}$ is expressed as eq. (6) and $\dot{q}_{l o s s}$ at the exit of the bed as eq. (7).

$\dot{q}_{r}=\left(1-F_{b}\right) \dot{m}_{a, i n} \frac{w_{i n}-w_{r}}{M_{v}} \Delta h_{r}^{0}$

$\dot{q}_{\text {heat }}=\dot{m}_{a, \text { in }}\left[\left(C p_{a}+w_{\text {out }} C p_{v}\right) T_{h, o u t}-\left(C p_{a}+w_{\text {in }} C p_{v}\right) T_{h, \text { in }}\right]$

$\dot{q}_{\text {loss }}=\dot{m}_{a, \text { in }}\left[\left(C p_{a}+w_{\text {out }} C p_{v}\right)\left(T_{h, \text { out }}-T_{63}\right)\right]$

For that $\mathrm{H} 3$ test, the thermal balance is presented in Figure 9. At the beginning of the test, the variation of internal energy in the reactor corresponds to the sensible heat accumulated by the solid salt, $\dot{\mathrm{q}}_{\text {sensibles }}$ and by the stainless-steel walls of the prototype. For this prototype, the mass of stainless steel in contact with the reactor bed and with the flowing air is about $200 \mathrm{~kg}$, thus the amount of heat accumulated in these walls is not negligible, and can be observed in Figure 9 as the area between the green and the blue curves, which corresponds to $0,43 \mathrm{kWh}$. One can thus observe a thermal steady state time of the salt bed of about $40 \mathrm{~min}$ and a longer thermal steady state establishment of the whole reactor, including the air diffuser and collector, of about $1 \mathrm{~h} 20 \mathrm{~min}$. This shows the importance of the choice of the walls of the reactor, as the thermal inertias of the reactor walls and ducts walls increase significantly the establishment time of the thermal steady state of the system.

Analysis of the experimental results of test $\mathrm{H} 3$ also shows that thermal losses from the bed can be neglected: as can be seen at steady state in Figure 9, the heat losses from the prototype to its surroundings are of the order of magnitude of $10 \mathrm{~W}$. At thermal steady state, the power output of the reactor is about $270 \mathrm{~W}$ in these conditions, which means a specific power of $3 \mathrm{~kW} / \mathrm{m}^{3}$ of reactor bed. As a comparison, tests performed previously ${ }^{[12]}$ with this salt in a fixed packed bed reactor reached a specific power of $2,96 \mathrm{~kW} / \mathrm{m}^{3}$. 


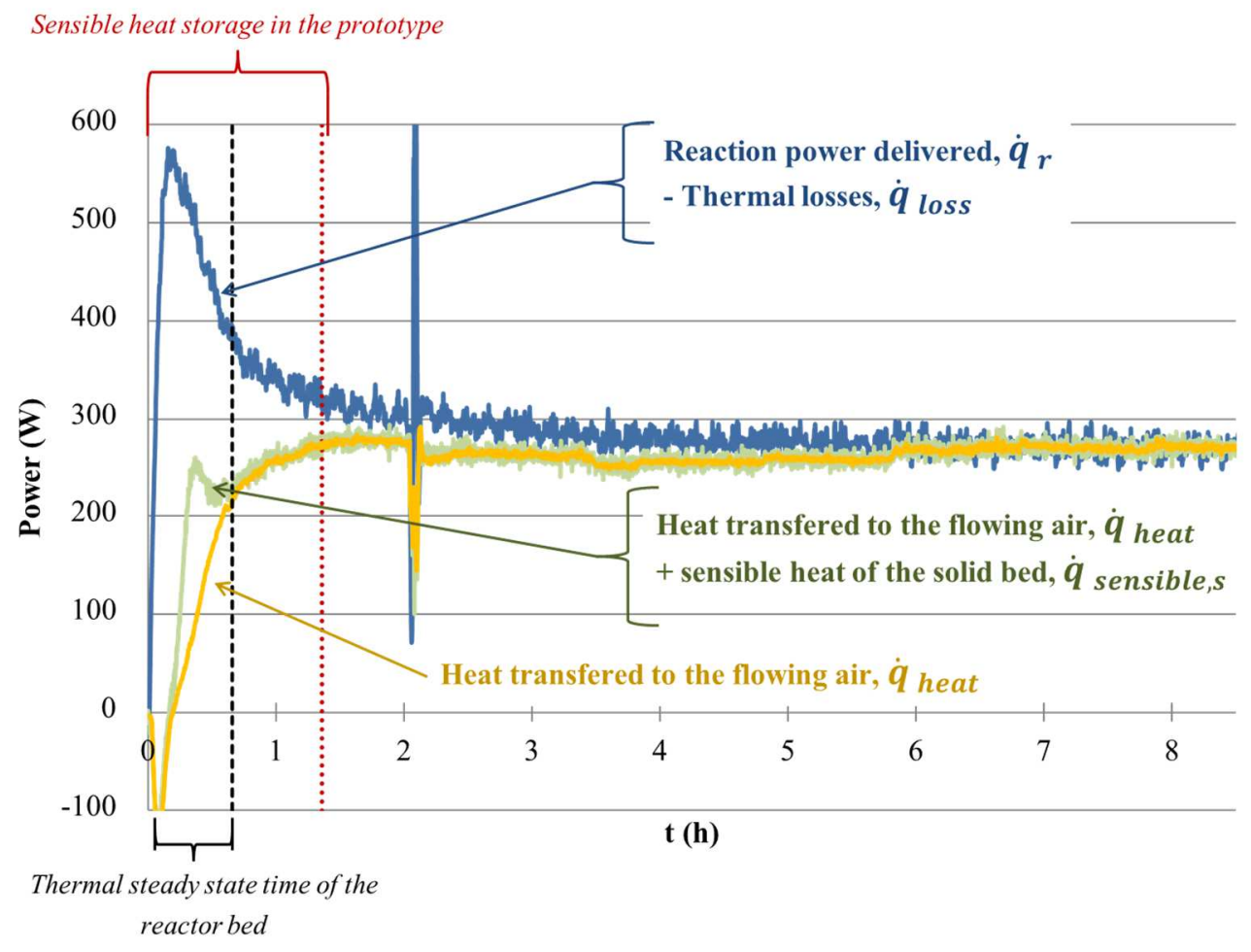

Figure 9 : Thermal balance during test $\mathrm{H3}$

\subsection{Experimental results: summary of the different tests and comparison}

From the results of the different discharging tests, it is possible, on the one hand, to check the repeatability of the experiments (comparison between $\mathrm{H} 3$ and $\mathrm{H} 4$ ), and on the other hand to assess the impact of the vapour mass fraction (H3 - H5), of the air flow (H2 - H5) and of the solid velocity (H3 H6) on the reactor performances. The main experimental results are presented in Table 2. The average bed temperature was calculated using thermocouples 28 to 37 and 48 to 57 . The analysis of these measurements reveals a good repeatability of the tests and shows the consistency of the results. The thermal power output and the reactor bed temperature depend essentially on the air humidity at the reactor inlet. Indeed, tests $\mathrm{H} 2$ and $\mathrm{H} 5$, which were carried out with a vapour mass fraction of $12 \mathrm{~g} / \mathrm{kg}$ (1880 $\mathrm{Pa}$ vapour pressure) have a higher reactor power than the others. The power of the $\mathrm{H} 2$ test is higher because the air flow is also higher and because H5 test presents a high bypass level. Similarly, tests $\mathrm{H} 3, \mathrm{H} 4$ and H6, which were conducted with a vapour mass fraction of $9 \mathrm{~g} / \mathrm{kg}$ (1400 Pa vapour pressure), present higher powers than test $\mathrm{H} 1$, whose vapour mass fraction was $4 \mathrm{~g} / \mathrm{kg}$ (640 Pa vapour pressure), although it was also performed with an air flow rate and inlet temperature higher than all other tests. The vapour mass fraction of the air at the reactor inlet is therefore an essential parameter for the performance of this system. However, this inlet humidity is not controlled in real systems in buildings and could be a limitation for the future use of these open TES systems.

Table 2 : Main experimental results at thermal steady state

\begin{tabular}{llll}
\hline Test number & Bypass factor $\mathrm{F}_{\mathrm{b}}$ & Reactor power $\dot{q}_{\text {heat }}$ & Average bed temperature \\
\hline
\end{tabular}




\begin{tabular}{lccc}
\hline & & $\left(\mathrm{kW} / \mathrm{m}^{3}\right)$ & $\left({ }^{\circ} \mathrm{C}\right)$ \\
\hline H1 & 0.21 & 1.76 & 29.8 \\
H2 & 0.23 & 4.57 & 41.0 \\
H3 & 0.33 & 3.00 & 36.2 \\
H4 & 0.26 & 2.56 & 36.3 \\
H5 & 0.44 & 2.56 & 38.5 \\
H6 & 0.31 & 2.00 & 34.5 \\
\hline
\end{tabular}

Figure 10 shows vertical temperature profiles at steady state in the bed for tests H3 and H6. The main difference between these tests is the velocity of the solid, 3 times higher for the H6 test. The small differences in average temperature between the two tests $\left(\mathrm{T}(\mathrm{H} 6)=34.5^{\circ} \mathrm{C}\right.$ and $\left.\mathrm{T}(\mathrm{H} 3)=36.2^{\circ} \mathrm{C}\right)$ can be explained by the small difference between the air inlet temperatures (Table 1) that influence the thermochemical equilibrium. The temperature profile appears less homogeneous when the velocity of the solid increases, and the bed temperature is lower at the top. Feeding an amount of cold solid at the top of the reactor causes this particular temperature profile.

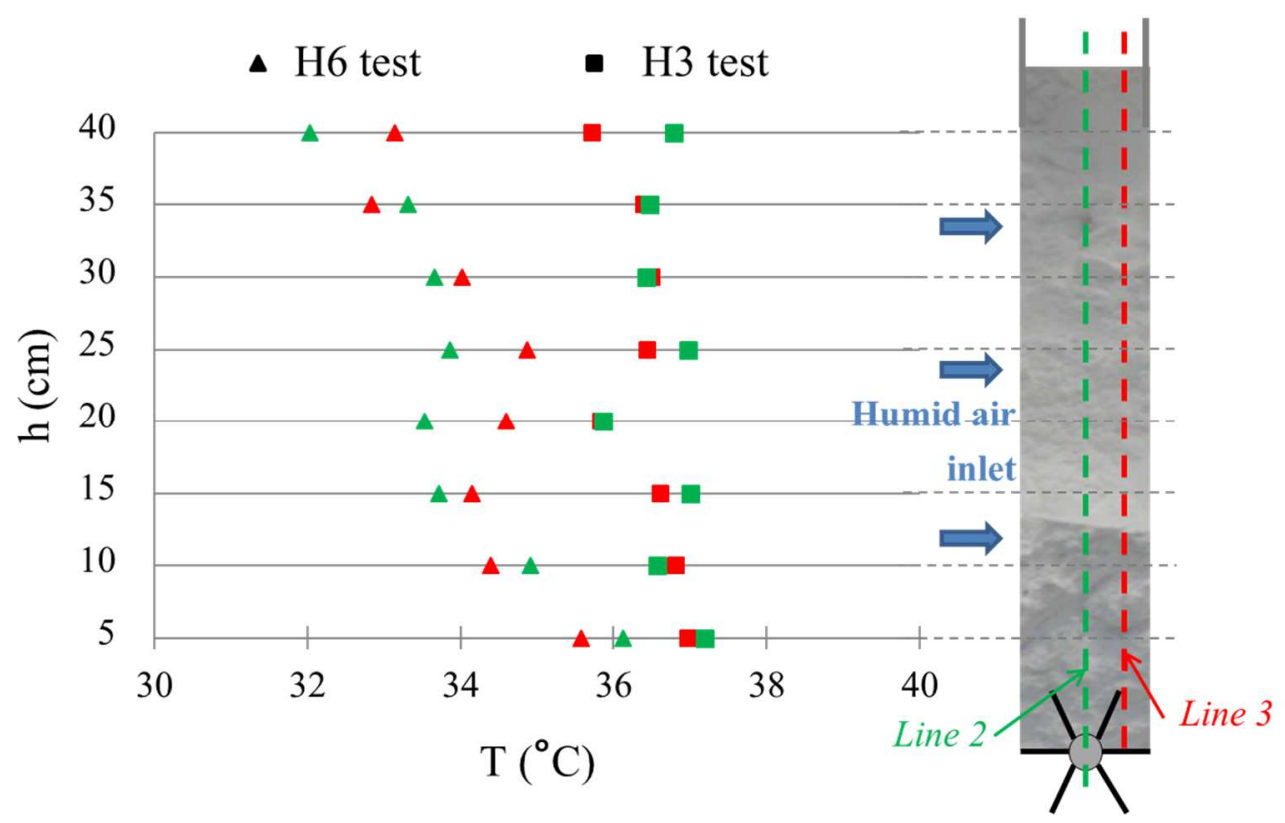

Figure 10: Comparison of tests $\mathrm{H} 3$ and H6: temperature profiles at thermal steady state in the bed (green dots: line 2, red dots: line 3)

Moreover, some phenomena were observed during all the tests:

- The thermal inertia of the reactor, which is related to heat accumulation in the solid phase and in metal walls of the prototype, lasted from 1 to $2 \mathrm{~h}$ (Figures 6, 7 and 9), which is significant at the scale of a single day but could be negligible for inter-seasonal thermal storage operations which can reach several hundreds of hours. In case of systems needing fast thermal responses, the inertia of the reactor and ducts walls should be carefully assessed as they represent about half of the thermal inertia of the system.

- Once the thermal steady state is reached, the temperature is homogeneous throughout the bed (Figure 7a): the temperature front that was expected following the numerical study was not observed, as these short experimental tests did not allow reaching the chemical steady state of the salt bed. 
- Moreover, difficulties were encountered during the tests, mainly linked to the solid flow inside the reactor. During preliminary tests without air flow through the bed, no blocking was observed and the solid flow was homogeneous. However, during both charging and discharging tests in conditions of high humidity of the air, some solid blocks and holes could be observed in the reactor (Figure 11). The reaction of the solid with water vapour thus could modify the salt flowing characteristics, due to the salt swelling and possibly to crystallisation of the salt in blocks at high relative humidity. This difficulty was handled by careful observation of the reactor during operation and vibrations applied to the reactor walls in critical conditions when inhomogeneity of the bed was detected. However, this solid flowing issue, that was already encountered during tests using solid adsorbents [15], would prevent the system from automating and should be further studied. Another consequence of the solid flowing inhomogeneity is the creation of air channelling, the development of large bypass factors of the reactor $\left(0.21 \leq F_{b} \leq 0.44\right)$, thus performances reached by the system were not as high as expected, as vapour could also flow without reacting with the salt through the bed cracks. Thus performances presented here could be improved by a better management of the solid flow.

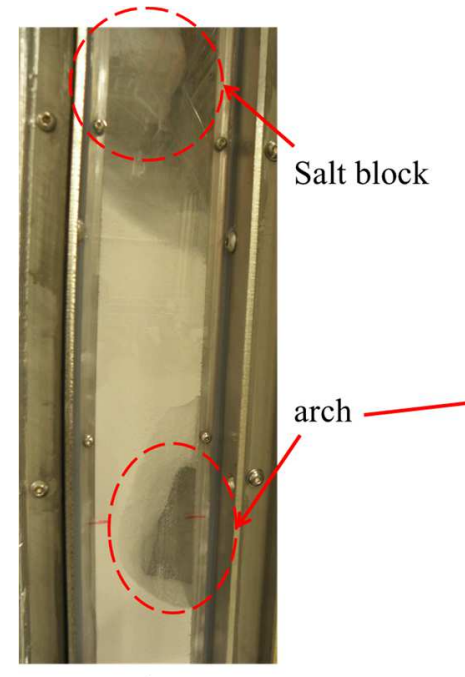

a)

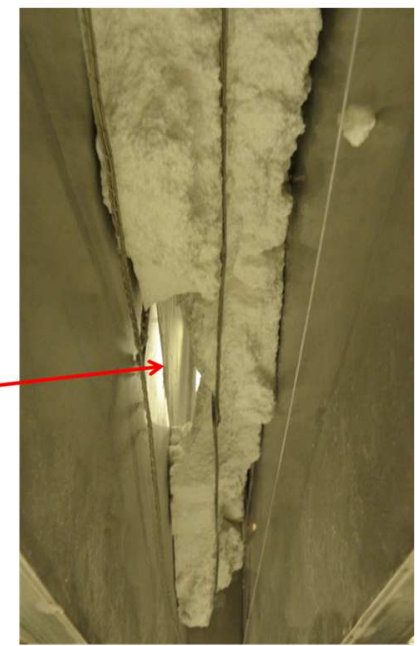

b)

Figure 11 : Pictures of the flowing inhomogeneity in the salt bed. a) Side view of the bed. b) View from the bottom of the bed (after disassembly of the rotary valve)

\section{Conclusion}

This study was a first step toward the development of a moving bed reactor using thermochemical salt for solar heat storage in buildings. A real scale prototype was developed and allowed testing the $\mathrm{SrBr}_{2}$ salt in a moving bed reactor, showing that this system is feasible and analyzing the functioning of the reactor with several air flows and water contents. In practice, these parameters change over time depending on the weather and building use. With constant parameters, once the thermal steady state was reached, the temperature was homogeneous throughout the bed. Reactor temperatures up to $41^{\circ} \mathrm{C}$ at thermal steady state and specific heating powers of 1.7 to $4.6 \mathrm{~kW} / \mathrm{m}^{3}$ of reactor bed were obtained. Due to the duration of the tests, it was not possible to compare the total extracted energy to theoretical values. This study nevertheless highlighted the impact of the air humidity at the reactor inlet on the reactor performance. Further development is still necessary concerning the solid 
flow inside the reactor, to insure better performance and possible automation of the system. For example, the use of composite material made with salt integrated into a matrix such as zeolites may solve the flow problem ${ }^{[27]}$. However, this solution lowers the energy density of the material ${ }^{[28]}$ and thus, the energy density of the system. Moreover, if an adequate material is found, more tests should be performed with the full reactor (and not just the half of it) so the top inert zones mentioned in section 2.1 can be filled and can reduce the air bypass issue. Moreover, longer tests (few days) have to be performed in order to reach chemical steady-state in the reactor. On a longer perspective, the economic questions of this technology will also have to be investigated.

\section{Acknowledgment}

This project has received support from the State Program "Investment for the Future" bearing the reference (ANR -10- IEED -0003) and from the departmental council of Savoie "Assemblée des Pays de Savoie". The help of Bertrand Chandez is acknowledged for the design and building of the prototype.

\section{Nomenclature}

\section{Latin symbols}

$\begin{array}{ll}C p & \text { Heat capacity }[\mathrm{kJ} /(\mathrm{kg} \cdot \mathrm{K})] \\ F_{b} & \text { Bypass factor }[-] \\ \mathrm{G} & \text { gas } \\ \mathrm{h} & \text { height in the reactor }[\mathrm{m}] \\ \mathrm{M} & \text { Molar mass }[\mathrm{g} / \mathrm{mol}] \\ \dot{m} & \text { Mass flow }[\mathrm{kg} / \mathrm{s}] \\ \mathrm{p} & \text { Pressure }[\mathrm{Pa}] \\ \dot{q} & \text { heating power }[\mathrm{W}] \\ \mathrm{R} & \text { Ideal gas constant }[\mathrm{J} /(\mathrm{mol} . \mathrm{K})] \\ \mathrm{RH} & \text { relative humidity of air } \\ \mathrm{S} & \text { solid } \\ \mathrm{T} & \text { Temperature }[\mathrm{K}] \\ \mathrm{W} & \text { Vapour mass fraction of the humid air }[\mathrm{g} \text { water } / \mathrm{kg} \text { dry air] } \\ \mathrm{X} & \text { advancement of the reaction }[-]\end{array}$

\section{Greek symbols}

$v \quad$ stoichiometric coefficient

$\Delta h_{r}^{0} \quad$ Reaction standard enthalpy $\left[\mathrm{kJ} / \mathrm{mol}_{\mathrm{v}}\right]$

$\Delta s_{r}^{0} \quad$ Reaction standard entropy $\left[\mathrm{kJ} /\left(\mathrm{mol}_{\mathrm{v}} . \mathrm{K}\right)\right]$

\section{Subscripts and superscripts}

$\begin{array}{ll}\text { 1/0 } & \text { solid type } \\ \text { a } & \text { dry air } \\ \text { bypass } & \text { through the channelling of the bed } \\ \text { el } & \text { electrical } \\ \text { eq } & \text { solid-gas equilibrium } \\ \text { h } & \text { humid air } \\ \text { heat } & \text { reactor heating } \\ \text { in } & \text { at the inlet } \\ \text { line'i } & \text { Line position of the thermocouple }\end{array}$




$\begin{array}{ll}\begin{array}{ll}\text { loss } \\ \text { number 'i' } \\ \text { out }\end{array} & \begin{array}{l}\text { losses to the surroundings } \\ \text { number of the thermocouple } \\ \text { at the outlet }\end{array} \\ \mathrm{r} & \begin{array}{l}\text { Reaction/ of the reactor bed } \\ \text { ref }\end{array} \\ \text { reference } \\ \text { sensible,s } & \text { sensible heat in the salt } \\ \text { th } & \text { thermal } \\ \mathrm{v} & \text { Water vapour }\end{array}$

\section{References}

[1] International Energy Agency. Key world energy statistics. 2017 (available online)

[2] Barzin R., Chen J. J., Young B.R., Farid M.M. Peak load shifting with energy storage and price-based control system, Energy, Vol. 92 (3), pp.505-514, 2015.

[3] López-Sabirón A.M., Royo P., Ferreira V.J., Aranda-Usón A., Ferreira G. Carbon footprint of a thermal energy storage system using phase change materials for industrial energy recovery to reduce the fossil fuel consumption, Appl. Energy, Vol. 135, pp. 616624, 2014.

[4] Zhang H. L., Baeyens J., Degrève J., Cáceres G., Segal R., Pitié F. Latent heat storage with tubular-encapsulated phase change materials (PCMs), Energy, Vol. 76, pp. 66-72, 2014.

[5] Tatsidjodoung P., Le Pierrès N., Luo L. A review of potential materials for thermal energy storage in building applications. Ren and Sustain En Reviews, Vol. 18 pp. 327-49, 2013.

[6] Cabeza L.F., Solé A., Barreneche C. Review on sorption materials and technologies for heat pumps and thermal energy storage, Ren. Energy, Vol. 110, pp. 3-39, 2017.

[7] Scapino L., Zondag, H.A. Van Bael J., Diriken J., Rindt C.M. Sorption heat storage for long-term low-temperature applications: A review on the advancements at material and prototype scale, Appl. Energy, Vol. 190, pp. 920-942, 2017.

[8] Guion J., Sauzade J.D., Laügt M. Critical examination and experimental determination of melting enthalpies and entropies of salt hydrates. Thermochim Acta, Vol. 67 pp. 167-79, 1983.

[9] Henninger S.K., Schmidt F.P. Henning H.-M. Water adsorption characteristics of novel materials for heat transformation applications. Appl Therm Eng, Vol. 30 pp. 1692-702, 2010 .

[10] Han S., Huang Y., Watanabe T., Nair S., Walton K. S., Sholl D.S., Carson Mereridh J. MOF stability and gas adsorption as a function of exposure to water, humid air, $\mathrm{SO}_{2}$, and $\mathrm{NO}_{2}$. Microporous Mesoporous Mat, Vol. 173 pp. 86-91, 2013.

[11] N'Tsoukpoe K.E., Schmidt T., Rammelberg H.U., Watts B.A., Ruck W.K.L. A systematic multi-step screening of numerous salt hydrates for low temperature thermochemical energy storage, Appl Energy, Vol. 124, pp. 1-16, 2014

[12] Michel B., Mazet N., Neveu P. Experimental investigation of an open thermochemical process operating with a hydrate salt for thermal storage of solar energy: Local reactive bed evolution, Appl Energy, Vol. 180, pp. 234-244, 2016

[13] Darkwa K., Ianakiev A., O'Callaghan P.W. Modelling and simulation of adsorption process in a fluidised bed thermochemical energy reactor. Appl Therm Eng, Vol. 26, pp. $838-45,2006$ 
[14] Neises M., Tescari S., de Oliveira L., Roeb M., Sattler C., Wong B. Solar-heated rotary kiln for thermochemical energy storage. Sol Energy, Vol. 86 pp. 3040-8, 2012.

[15] Kerskes H., Mette B., Bertsch F., Asenbeck S., Drück H. Chemical energy storage using reversible solid/gas-reactions (CWS) - results of the research project. Energy Proc, Vol. 30 pp. 294-304, 2012

[16] Stutz B., Le Pierrès N., Kuznik F., Johannes K., Palomo Del Barrio E., Bédécarrats J.-P., Gibout S., Marty P., Zalewski L., Soto J., Mazet N., Olives R., Bezian J.-J., Pham Minh D. Storage of thermal solar energy, Comptes Rendus Phys. Vol. 18, pp. 401-414, 2017.

[17] Michel B., Neveu P., Mazet N. Comparison of closed and open thermochemical processes, for long-term thermal energy storage applications. Energy, Vol.72 pp. 702-16, 2014.

[18] Bales C. Laboratory Tests of Chemical Reactions and Prototype Sorption Storage Units, A Report of IEA Solar Heating and Cooling programme - Task 32. [http://task32.ieashc.org/Data/Sites/1/publications/task32-b4.pdf], 2008.

[19] Mauran S., Lahmidi H., Goetz V. Solar heating and cooling by a thermo-chemical process. First experiments of a prototype storing $60 \mathrm{kWh}$ by a solid/gas reaction. Sol Energy, Vol. 82 (7) pp. 623-36, 2008.

[20] Pardo P., Anxionnaz-Minvielle Z., Rougé S., Cognet P., Cabassud M. $\mathrm{Ca}(\mathrm{OH})_{2} / \mathrm{CaO}$ reversible reaction in a fluidized bed reactor for thermochemical heat storage, Sol Energy, Vol. 107, pp. 605-616, 2014.

[21] Stach H., Mugele J., Jänchen J., Weiler E. Influence of cycle temperatures on the thermochemical heat storage densities in the systems water/microporous and water/mesoporous adsorbents, Adsorption, Vol. 11, pp. 393-404, 2005.

[22] D’Ans P., Courbon E., Frère M., Descy G., Segato T., Degrez M. Severe corrosion of steel and copper by strontium bromide in thermochemical heat storage reactors, Corrosion Science, Vol. 138, pp. 275-283, 2018.

[23] Farcot L., Le Pierrès N., Michel B., Fourmigué J.-F., Papillon P. Numerical investigations of a continuous thermochemical heat storage reactor, Journal of Energy Storage, Vol. 20, pp. 109-119, 2018.

[24] Marias F., Neveu P., Tanguy G., Papillon P., Thermodynamic analysis and experimental study of solid/gas reactor operating in open mode, Energy, Vol. 66, pp. 757-765, 2014.

[25] D.D. Wagmann, W.H. Evans, V.B. Parker, I. Halow, S.M. et al Bailey. The NBS tables of chemical thermodynamic properties. Selected values for inorganic and C1 and C2 organic substances in SI units. J Phys Chem, Vol. 11, pp. 2.1-2.385, 1982.

[26] Johannes K., Kuznik F., Hubert J.-L., Durier F., Obrecht C. Design and characterisation of a high powered energy dense zeolite thermal energy storage system for buildings. Appl Energy, Vol. 159, pp. 80-86, 2016.

[27] Wyttenbach J., Bougard J., Descy G., Skrylnyk O., Cournon E., Frère M., Bruyat F. Performances and modelling of a circular moving bed thermochemical reactor for seasonal storage. Appl Energy, Vol. 230, pp. 803-815, 2018.

[28] Courbon E., D’Ans P., Permyakova A., Skrylnyk O., A new composite sorbent based on $\mathrm{SrBr}_{2}$ and silica gel for solar energy storage application with high energy storage density and stability. Appl Energy, Vol. 190, pp. 1184-1194, 2017. 